Comment

\section{-to: Weets I, Kaufman L, Van der Auwera B et al. (2004) Seasonality in clinical onset of Type 1 diabetes in Belgian patients above the age of 10 is restricted to HLA-DQ2/DQ8- negative males, which explains the male to female excess in incidence. Diabetologia 47:614-621}

To the Editor: I read the paper by Weets and co-workers [1] reporting seasonality of onset of Type 1 diabetes in HLA$D Q 2 / D Q 8$-negative Belgian males with interest. One of the possible environmental factors that vary with season in Europeans and are discussed by the authors of this paper as possible determinants of Type 1 diabetes is vitamin D deficiency, a factor which might explain the authors' findings as a result of interactions with genetic factors.

In view of the existing literature, showing an association between dietary supplementation with vitamin D in childhood (and in one study up to the age of 30) and both protection from and reduced odds ratios for risk of Type 1 diabetes in Europeans, it is reasonable to expect this phenomenon to extend to Belgium [2, 3, 4]. Moreover, since vitamin D status varies with season in pregnancy and pregnant women in Europe can have vitamin D deficiency [5], I wonder whether including the season of birth in the analyses as a surrogate for maternal (and hence also perinatal) vitamin D status might reveal additional associations with genotype? In particular, findings with the

DOI 10.1007/s00125-004-1539-8

Received: 27 May 2004 / Accepted: 28 July 2004

Published online: 22 October 2004

(C) Springer-Verlag 2004
$V D R$ genotype would be of especial interest, if available. Alternatively, if Belgian women are fully supplemented with vitamin $\mathrm{D}$ in pregnancy this might eliminate vitamin $\mathrm{D}$ status as an interacting factor and that would be useful additional information about the study by Weets and co-workers.

\section{B. J. Boucher}

Centre for Diabetes \& Metabolic Medicine,

Bart's \& the London MDS, Queen Mary,

University of London, Royal London Hospital, London, UK

\section{References}

1. Weets I, Kaufman L, Van der Auwera B et al. (2004) Seasonality in clinical onset of Type 1 diabetes in Belgian patients above the age of 10 is restricted to $H L A-D Q 2 / D Q 8$ negative males, which explains the male to female excess in incidence. Diabetologia 47:614-621

2. EURODIAB Study Group 2 (1999) Vitamin D supplement in early childhood and risk for Type 1 (insulin-dependent) diabetes mellitus. The EURODIAB Substudy 2 Study Group. Diabetologia 42:51-54

3. Stene LC, Joner G (2003) Use of cod liver oil during the first year of life is associated with lower risk of childhoodonset type 1 diabetes: a large population-based, case-control study. Am J Clin Nutr 78:1128-1134

4. Hypponen E, Laara E, Reunanen A et al. (2001) Intake of vitamin $\mathrm{D}$ and risk of type 1 diabetes: a birth-cohort study. Lancet 358:1500-1503

5. Boucher BJ, Robinson S, Shore S et al. (2003) Maternal vitamin D status contributes inversely to cord proinsulin and directly to abdominal girth in white babies born in southern England. Ped Res 53:14A

\section{B. J. Boucher $(\bowtie)$}

Centre for Diabetes \& Metabolic Medicine,

Bart's \& the London MDS, Queen Mary,

University of London, Royal London Hospital,

London, E11BB, UK

E-mail: bboucher@ doctors.org.uk

Tel.: +44-1243-811230, Fax: +44-1243-811924 